\title{
ALGUNOS ASPECTOS DE LA TÉCNICA DEL MONÓLOGO INTERIOR EN LA ÚLTIMA NOVELÍSTICA DE CAMILO JOSÉ CELA
}

DiEUdonNE MENDOgo MinsonguI

Universidad de Yaounde, I (Camerün)

Nuestro objetivo consiste en poner de relieve algunas de las características del monólogo interior en la última creación literaria del premio Nobel español, es un aspecto que parecería desapercibido a primera vista, pero a nuestro modesto entender pensamos que es uno de los aspectos más importantes -en cuanto a técnicas literarias nos referimos-, de dicha creación literaria. El presente artículo dadas las limitaciones que nos son impuestas, tendrá un carácter orientativo y metodológico.

Como características fundamentales de esta técnica literaria, Silvia Burunat $^{1}$ destaca entre otras tres a saber la memoria, el argumento y la puntuación. Para nosotros éstas son las más llamativas, a continuación vamos a ver cómo van manifestándose en la novelística de nuestro autor.

1 SilviA BURUNAT:: «El monologo interior. Su naturaleza», en El monólogo interior como forma narrativa en la novela española (1940-1975). Madrid:: JOSÉ PORRÚA TURANZAS, 1980, pags. 3-36. 


\section{LA MEMORIA}

En opinión de Silvia Burunat ${ }^{2}$, conciencia y memoria son términos paralelos. La conciencia aparece identificada con la memoria en cuanto significa consevación y acumulación del pasado en el presente. A continuación nuestra crítica afirma que la memoria es un factor condicionante de la novela contemporánea:

«En la memoria, el ser se vuelve continuo y aparece como un rio que fluye sin interrupción, el río de la conciencia. La memoria es un factor condicionante en todo proceso mental y por lo tanto constituye la esencia de la novela contemporánea... Bergson analiza este fenómeno desde los puntos de vista metafísico y estético. El establece una diferencia entre dos clases de memoria la involuntaria y la voluntaria. Esta última nos revela los aspectos de razón y voluntad del ser y nos muestra las imágenes del pasado que se corresponden a la vida práctica, es decir, que tienen significación utilitaria.

Para el artista creador, la memoria que más interesa es la involuntaria, mediante la cual todo el pasado se acumula en la conciencia por la mera necesidad de su propia naturaleza, es decir, de la naturaleza de la memoria.

Esta es la memoria por excelencia, según Bergson, que es perfecta y eterna y su validez proviene de la realidad misma y no de ningún proceso intelectual. Este recordar involuntario, espontáneo, se presenta a intervalos en forma de flash y desaparece en cuanto la memoria voluntaria interviene.

Mediante el empleo de esta memoria, el novelista contemporáneo expresa un sentido de la realidad que es a la vez vital y dinámico y que alcanza una mezcla perfecta del pasado con el presente» ${ }^{3}$.

En la novela celiana, podemos afirmar que la memoria desempeña un papel importante como proceso de creación.

En San Camilo 1936, por ejemplo, la guerra civil española, vista de la distancia de la historia, está vivida, sin embargo, con la intensidad que da la intimidad del recuerdo. La memoria, en este caso, es pues un elemento temático reiterado en la narración, dentro de la disyuntiva de evadir o aceptar la culpa:

"No le des vueltas a la noria de la memoria, a la noria de la memoria, a la noria, huye, todavía puedes huir...» (pág. 60).

2 Ibrdem, pags. 7-8.

3 Ibidem, pág. 8. 
Pero más adelante:

"haz lo posible para no huir, mantente firme...» (pág. 63).

La misma idea se reitera a continuación:

*No huyas, mirate al espejo cada mañana y procura mantener el tipo como el torero o como el gladiador...» (pág. 83).

En otro lugar de la novela se dice:

*Nadie sabe qué es mejor si recordar u olvidar, el recuerdo es con frecuencia triste y el olvido en cambio suele ser muy compensador y cicatrizante, aleja los malos pensamientos...» (pág. 95).

Para Cela la memoria nos convertiría a todos en cobardes, sobre todo en relación con la muerte. Pero también en eso descubriría un sentimiento angustiante de culpa, y de ahí que el narrador quiera mantenerse firme ante el espejo para no escapar de sí mismo, de su memoria recriminadora:

«La gente no suele dar importancia a la memoria y al final se estrella contra un muro de muertos impasibles, de muertos acusadores, hieráditos e impasibles. La gente no suele creer que la memoria lastra y da aplomo al sentimiento" (pág. 156).

Acerca de esta novela Silvia Burunat afirma en relación con el aspecto que tratamos:

«Los recuerdos constituyen un recurso formal. Como se trata del "stream of consciousness" del narrador, esos recuerdos se presentan en forma confusa y heterogénea, pero están agrupados a la vez en línea continua. La novela está estructurada en forma simétrica. $A$ la división que ya habiamos señalado de vísperas, festividad y octava de San Camilo corresponden cuatro partes a las vísperas y cuatro a la octava. La festividad no está dividida El epilogo, repetimos, tiene carácter pedagógico. Esa simetría se debe a que el contenido de la novela es pretérito, por lo tanto no hay nada casual en ella, nada gratuito, todo se sabe de antemano, es decir, lo sabe el narrador, que lo cuenta extraído de su memoria»"

4 Ibídem, pág. 75. 
En la última novelística de nuestro autor, la memoria desempeña un papel importante, por ser uno de los ejes centrales sobre los cuales van estructuradas las dos novelas. Este aspecto se hace más patente en Mazurca para dos muertos por varias razones que iremos desvelando a continuación. En una de sus entrevistas, el propio Camilo José Cela ha afirmado que para escribir esta novela, ha procedido por el recuerdo:

¿Porqué escribir una novela gallega en Mallorca?

- Galicia me la conozco de memoria, como la palma de mi mano $y$ en donde he tenido una gran cantidad de vivencias, pero como "Mazurca" no es una crónica o un reportaje sino una novela, no es preciso estar allí, sino que se procede por el recuerdo... ${ }^{5}$.

Luego, no olvidemos que la novela se abre con una cita de Ulalume de Edgar A. Poe (1809-1849)::

«... Our thoughts they were palsied and sere, Our memories were treacherous and sere».

El frontispicio del relato, es decir, esta cita de Poe, va a ser el eje sobre el cual Robín Lebozán va a construir su escritura y, más profundamente, el mismo Camilo José Cela. En dos ocasiones evoca la sentencia del escritor norteamericano. En la primera directamente:

"-Si, Poe tiene razón, nuestros pensamientos son lentos y monótonos, y nuestros recuerdos son traidores y marchitos y están oxidados como navajas, se conoce que son asi, debe ser su naturaleza” (pp. 121-122).

En la segunda, de nuevo traduce la cita de Poe en diálogo consigo mismo:

«... acuérdate otra vez de Poe, nuestros pensamientos eran lentos y marchitos, nuestros recuerdos eran traidores y marchitos, (y apostilla) a mi me gustaría no tener ni pensamientos ni recuerdos pero no puedo, a mi me gustaría ser como las rosas y las madreselvas, que no tienen más que sensaciones, quizá los bichos muy pequeños y débiles, las lamáchegas, el caballito del demonio, tengan el ánima hueca y sin consuelo como las rosas y las madreselvas» (pág. 233).

5 Se trata de una entrevista de C.J. Cela con J.M. Plaza aparecida en Diario 16, Liber 83, $\mathrm{N}^{\circ}$ 143, 2 de octubre de 1983, pág. 2. 
En la novela sabemos también que Robín Lebozán Castro de Cela es, además de un lector consumado de literatura, un creador literario que evoca y plasma sus recuerdos y vivencias. Además conviene destacar el importante papel que desempeña Ádega tanto desde el punto de vista narrativo como del dramático. Si nos fijamos detenidamente en ella, llegamos a la conclusión de que ella es la cronista por excelencia de esta historia, es también la memoria del monte, conoce la historia familiar, la historia de todo el monte y la de todo el país. Así como Robín Lebozán es el escritor por excelencia de esta historia. Hay una diferencia entre Ádega y los demás actores que contribuyen a la historia de la novela. Todos los actores, excepto ella, se caracterizan por su formación intelectual; Ádega es diferente en cuanto a su formación personal. Sólo es una mujer del pueblo que posee la típica formación y sabiduría popular, conoce muchos cuentos del país y la bibliografía de casi todos sus paisanos, por lo tanto, su testimonio es válido, y su voz digana de confianza, ya que además, entre sus cualidades personales, cuenta con la de tener muy buena memoria. Esto es muy importante en cuanto a la estructura de la novela, porque sus materiales narrativos están constituidos por recuerdos y testimonios orales, principalmente. Por fin conviene subrayar que Mazurca para dos muertos entraña, pues, una experiencia estética que remite al acto de la memorio como único método de aprehensión de la realidad. Cobran, así, todo su sentido los versos de Poe con los que se abre el libro y que Robín Lebozán parafrasea significativamente. Existiría, pues una metáfora implícita en la novela, según la cual los mecanismos del recuerdo son similares a los de la composición de una novela y vice versa. En este caso, la memoria así pues es vida, ya que a partir del pasado da significado al presente y nos remite tanto a la vida como al arte.

En Cristo versus Arizona, a lo largo del relato, el narrador está obsesionado por la reconstrucción escrupulosa de su(s) historia(s), en ese afán de reconstrucción, la memoria desempeñaría un papel fundamental igual que en Mazurca para dos muertos. En una ocasión, el narrador afirma:

*... el orden de cada instante no puede saberlo nadie y mucho menos recordarlo...* (pág. 184).

Esto significaría que la memoria jugaría un papel acumulativo, permitiría al narrador acumular recuerdos dentro de los recuerdos con un grado mínimo de estratificación. La voz del narrador, recordemos, funciona como una cámara cinematográfica, por planos de alejamiento y aproximación. Cuando se ha agotado la perspectiva, el narrador se hace a un lado y cede el punto de vista al interlocutor más próximo:

*... ahora me dice mi amigo Sandy Hartford que...» (pág. 185). 
A veces la pérdida de la memoria provoca la caotización del hilo narrativo: *... Cada día pierdo más memoria... (pág. 219).

O también la duda acerca de la veracidad de los hechos; abundan ejemplos en el relato:

*... es probable de Bill Hiena Quijotoa se llame Mike San Pedro, es probable que los dos sean el mismo» (pág. 47).

En otra ocasión se dice:

*... era una mujer, ¿se llamaba Corazón Leonarda? ¿se llamaba Mandy Mesilla? ¿se llamaba Noelia Chunda?...» (pág. 48), etc...

Como podemos notar en todo cuanto precede, la memoria como afirma Silva Burunat es un factor condicionante para la novela actual; a este respecto, nuestro autor no podía hacer excepción porque como venimos exponiendo, es uno de los elementos estructurales de sus novelas como atestiguan respectivamente San Camilo 1936, Mazurca para dos muertos y Cristo versus Arizona.

\section{El ARGUMENTo}

En opinión de Silvia Burunat ${ }^{6}$, la novela de «stream of consciousness» carece de argumento. a este respecto nos ofrece el punto de vista siguiente:

*Este autor está obligado a representar el caso y los accidentes de la mente, de la conciencia, sin patrón, sin disciplina ni claridad. El arte requiere patrón, disciplina y claridad. El lector exige estas cosas para entender e interpretar la obra literaria. Por lo tanto, el autor, el escritor tiene que imponer de una forma u otra esas cosas en su obra. Pero al escritor de "stream of consciousness" no le interesa el argumento en un sentido corriente. Le interesan más los procesos psíquicos que las acciones fisicas. Este escritor tiene que valerse de una serie de patrones entre los que podemos enumerar los siguientes: las

6 Silvia Burunat, obr. cit., pág. 24. 
unidades (de tiempo, lugar, carácter y acción), los "leitmotifs", los patrones literarios, pre-establecidos, burlescos o de parodia, las estructuras simbólicas, los arreglos escénicos formales, los esquemas cíclicos naturales (estaciones mares, etc) y los esquemas ciclicos teóricos (estructuras musicales, ciclos históricos, etc)».

La última novela de Cela o sea Cristo versus Arizona que obedece más a la técnica de «stream of consciousness», carece de argumento. Es la opinión de varios críticos que compartimos también. Entre dichos críticos destaca la opinión del comentarista de $\mathrm{Ya}$, con motivo de la concesión del premio Nobel de literatura a C.J. Cela, afirmaba:

*... Sin embargo, en 1988 publicó Cristo versus Arizona, una novela que él mismo definió como de aventuras. Lo que pasa es que es una novela de aventuras sin argumento alguno»?

Si las novelas de este tipo carecen de argumento, en cambio uno de los patrones más importantes va a ser el «leitmotif» según nuestra crítica:

"Uno de los patrones más importantes para alcanzar la interpretación de una obra de este tipo es el "leitmotif" ${ }^{8}$.

En opinión de Mariano Baquero Goyanes ${ }^{9}$, el «leitmotif» es uno de los procedimientos más utilizados en orden a conseguir una estructura novelesca aproximable a la musical.

Por su parte Silvia Burunat ${ }^{10}$ opina que es un término musical. Consiste en una frase melódica señalada o un paisaje corto que expresa o se asocia con una idea, persona o situación determiandas y que la acompaña cada vez que vuelve a aparecer. A continuación, dice que en la literatura, el «leitmotif» se puede definir como una imagen, símbolo, palabra o frase que se repite y que acarrea una asociación estética con una idea o un tema. $\mathrm{El}$ «leitmotif» lleva temas menores a través de la novela y expresa, con el poder de la imagen y del símbolo, lo que existe en la mente de los personajes. Además sirve de eslabón para ayudar a mantener cierta unión dentro del material desunido o dividido de la conciencia.

7 «Un caminante de Padrón que se hizo universal», $Y a, \mathrm{~N}^{\circ} 16.257$, viernes, 20 de octubre de 1989 , pág. 6.

8 Silvia Burunat, obr. cit., págs. 24-25.

9 Marlano Baquero Goyanes: Estructuras de la novela actual. Barcelona: Planeta, 1975, 3* ed., pág. 98.

10 Silvia Burunat, obr. cit., pág. 25. 
Nuestro autor sin duda alguna se vale de los «leitmotifs» en su novelística. En San Camilo 1936, podemos decir que el uso de los «leitmotifs» es abusivo a pesar de la gran complejidad de la obra. Nosotros nos atendremos solamente a los aspectos más llamativos. El primer «leitmotif» que llama la atención es el «mirarse al espejon. Sabemos que San Camilo 1936, comienza, precisamente, con el narrador enfrentado con su propia imagen ante el espejo, hurgando en la profundidad de su conciencia y viendo en ella reflejado al otro, a ese otro que es él y no es él al mismo tiempo. «El mirarse en el espejo» se convierte así en «lemotif» y principal recurso estructural de todo el relato. Pero el simbolismo ontológico del espejo, tan frecuentemente usado en la novela contemporánea en relación con el tema de la búsqueda de la identidad, adquiere aquí un significado adicional: el ser imagen de la conciencia culpable. Culpabilidad y auto-conocimiento están profundamente relacionados en esta novela. El individuo se siente perdido en medio de las circunstancias caóticas del mundo, y por eso busca desesperadamente encontrarse a sí mismo mediante la práctica precaria e inquietante de verse uno mismo convertido en objeto. Frente al espejo, el narrador protagonista se angustia debido al fenómeno de enajenación y desdoblamiento propio de la conciencia reflejada, y en este sentido él mismo se tutea con duda y desconfianza. Enfrentado con el abismo insondable de su yo, metido como él mismo dice:

«en un hondo pozo de oscuridad» (pág. 428).

El espejo tiene para él la paradójica fascinación de doble de la vida y la muerte. El motivo literario de «mírate en el espejo» va acompañado de la tentación de huída, pero la conciencia -espejo ofrece su llamada irrevocable al hombre de buena fe que se dispone a asumir su responsabilidad y su ser-culpable en medio del mundo:

"tú no puedes librarte de tu espejo pero tampoco quieres..." (pag. 304).

En la novela destacan otros «leitmotifs» relacionados directamente con la muerte como son la «sangre», las «moscas», etc.

Además, el progratonista de San Camilo 1936, que tiene mucho del propio Cela de aquellos tiempos, es al mismo tiempo un prototipo y un ente individual. Se mira en el espajo y se compara con diversos personajes históricos: Napoleón, el rey Cirilo de Inglaterra, Julio César, San Pablo, el Cid, Búfalo Bill. Según Paul Ilie ${ }^{11}$,

11 Paul Llite: La novelistica de Camilo José Cela. Madrid: Gredos 1978, 3* ed., pág. 314. 
el argumento clave de la novela trata de una violencia permeable que no sólo desciende verticalmente por entre los estratos sociales de 1936, sino que persiste a través de un continuo de acontecimientos temporales que se extienden durante siglos de experiencia nacional española. A este respecto los «leitmotifs» de «el rey Cirilo» y «Napoleón» ilustran estos, al ampliar la dimensión diacrónica de la violencia dentro del continuo histórico. Estos motivos, aunque vacíos de contenido intelectual, unifican la novela como dos de los recursos más insistentes del monólogo. Ellos crean la profundidad temporal necesaria para provocar la ilusión de que viene dándose, en términos históricos, una continuidad en la violencia nacional.

En Mazurca para dos muertos, hay varios y diversos «leitmotifs» que acentúan rítmicamente, como en una salmodia, la intensidad lírica, épica, simbólica e incluso mágica del libro. Destacaríamos los siguientes:

- La lluvia, el orvallo constante.

- La raya del monte (que borra detrás de la lluvia silenciosa).

- El eje del carro de bueyes.

- Ciertos animales: la rana, la raposa, el lobo, el jabalí, la donosiña...

- La laguna de Antela donde duerme la ciudad de Antioquía.

- La fuente del Miangueiro que lava los huesos de los muertos.

- Las nueve señales del «hijoputa».

- Los moros.

- Los muertos.

- Los pezones de Benicia, como castañas.

- La mazurca del ciego Gaudencio, «ma petite Marianne».

Es posible que haya alguno más, pero pensamos que éstos, al menos son los más destacados.

En Cristo versus Arizona, los «leitmotifs» se corresponden a la distintas letanías:

- La «letanía» de carácter histórico o político (el corrido).

- La «letanía» religiosa (la letanía de nuestro señor), el «leitmotif» más llamativo de la novela.

- La «letanía» erótica: la que reza la fornicadora Cyndy.

Son estas «letanías» que confieren a la novela su estructura musical.

\section{LA PUNTUACIÓN}

Es el último aspecto entre los fundamentales que destaca nuestra crítica, he aquí lo que dice textualmente: 
"En cuanto a los recursos mecánicos, el autor de "stream of consciousness" suele alterar los sistemas de puntuación ${ }^{12}$.

Al estudiar el monologo de Molly Bloom en Ulyses, Silvia Burunat ${ }^{13}$ afirma que no hay puntuación alguna. Mediante esta omisión, Joyce logra presentarnos el fluir de la conciencia de Molly en un estado cercano al sueño. La ausencia de puntuación constituye un recurso enteramente visual, ya que el monólogo mismo está presentado con extremo cuidado en cuanto a la ordenación de la frases.

Nuestro autor altera también los sitemas de puntuación.

San Camilo 1936 se basa grandemente en la evocación de aquellos días que precedieron a la guerra civil española con todas sus sensaciones y obsesiones, sus vulgaridades, experiencias y cotidianidades. La obra resulta una verdadera epopeya sin protagonistas reales, que se nos aparece como una masa de recuerdos en unas cuatrocientas páginas sin puntos y sin apartes. Varios estudiosos han destacado esta alteración de los sistemas de puntuación en esta novela. José Domingo ${ }^{14}$ afirma por ejemplo:

*... Adopta Cela en su novela algunas de las innovaciones de la novelística internacional de nuestros días: alternancia de distintas acciones sin signos de separación; yuxtaposición de diálogos y parte expositiva sin solución de continuidad; anarquía de puntuación; intercalación en el texto de noticias y anuncios extraídos de la prensa del tiempo, a modo de Collage literario, lo que contribuye a centrar con el máximo colorido y fidelidad el ambiente del Madrid de entonces».

Por su parte y en la misma perspectiva, Mariano Tudela ${ }^{15}$ dice:

*La novela, el estirado y crepitante monólogo, está tramado por una obsesiva sucesión de palabras, apenas ni el engarce de puntos y comas».

La ausencia de puntuación es notable también en Oficio de Tinieblas 5. A este respecto, Silvia Burunat ${ }^{16}$ afirma:

12 Silvia BuRunat, obr. cit., pág. 27.

13 Ibidem, pág. 27.

14 JOSE DOMINGO: 1. La novela española del siglo XX. 2. De la postguerra a nuestros días. Barcelona: Nueva Colección Labor, 1973, pág. 46.

15 Marlano Tudela: Cela: Grandes escritores contemporáneos. Madrid: Espesa (Agisa), 1969, pág. 99.

16 Silvia Burunat, obr. cit., pág. 79. 
* La ausencia de puntuación le presta a Oficio de Tinieblas 5 una estructura musical fluida, articulada sintácticamente, pero con silencios «staccatos» y frases sostenidas. En este aspecto y en los de obra surrealista se puede comparar con la obra poética del propio Cela, de sus años juveniles, Pisando la dudosa luz del día...»

En la última novela de nuestro autor o sea Cristo versus Arizona, la alteración de la puntuación es muy notable; varios críticos han destacado este aspecto. Cristo versus Arizona es una narración a base de «comas», lo cual lleva a Julio Calviño ${ }^{17}$ a afirmar que:

$$
\text { «La primera frase es todas las frases...». }
$$

En opinión de José García Nieto ${ }^{18}$ :

*... Y Cristo versos -hacia, en este caso-Arizona, Dios en todas partes, Cristo hacia todas partes, esas partes horribles contadas sin descanso - no se asusten si les digo que en las trescientas y pico de páginas no hay un solo punto-...*

Leopoldo Azancot ${ }^{19}$ por su parte incluye en su comentario un subtítulo «Sólo comas» y que explica a continuación:

*Lo que, al parecer, pretendió Cela fue, de acuerdo con su concepción verbalista y lúdica de la literatura, realizar un ejercicio literario que pasmara, divertiera y escandalizara a un tiempo, de acuerdo con una fórmula que, sobre el papel, parece infalible para conseguir el éxito, pero que, en la práctica, no lo es, según prueba, en concreto, "Cristo versus Arizona". En efecto el gusto por una modernidad que es pura apariencia ha movido a Cela a escribir su libro sin otro signo de puntuación que la coma, y ello -a pesar de que, en muchos casos, la coma reemplaza aquí, arbitrariamente, a los otros signos de puntuación: numerosas oraciones están compuestas en función de la totalidad de los mismos - le ha impuesto limitaciones sintácticas que le han vedado desarrollar sus posibilidades en lo que constituye

17 Julio CalviÑo: «El texto vampiro. A propósito de Cristo versus Arizona», Insula, $\mathrm{N}^{\circ} 498$, mayo de 1988, pág. 13.

18 José GarCla Nieto: «Cristo versus Arizona», A.B.C. literario, 27 de febrero de 1988, pág. 3.

19 LEOPOLDO AZANCOT: «Una invención sobre el Oeste americano», El pats, 28 de febrero de 1988, pág. 11. 
de siempre su campo de máxima excelencia: el de lo verbal - con lo que no se alcanza el pasmo buscado por lo que hace al dominio de las técnicas de estilo...*

Manuel Alvar ${ }^{20}$ por su lado se hace varias preguntas acerca del género «novela»:

* Esta es la cuestión que el crítico debe encarar cuando valora este relato. ¿Hasta dónde lo novelesco? ¿O es novela el conjunto de elementos que lo integran? Porque desde la primera línea de la página cinco hasta la ventinueve de la página doscientas treinta y ocho no se encuentra otro signo de puntuación que la coma....

En opinión de Juan Antonio Masoliver Ródenas ${ }^{21}$ :

"Cristo versus Arizona, sorprendente desde su mismo título, es una novela que carece de argumento, carece de protagonista cuenta con más de quinientos personajes y se sucede en un continuo flujo narrativo ininterrumpido solamente por las comas y por un único punto: el que señala el final del librox.

Las tres características fundamentales de la técnica del monólogo interior señaladas a saber la memoria el argumento y la puntuación están presentes en la novelística de C.J. Cela. A nuestro modesto entender, la técnica del monólogo interior es una de las características de la última novelística de nuestro autor y esperemos que llame la atención de los estudiosos de la materia.

\section{Bibliografía de Camilo José Cela utilizada}

- Visperas, Festividad y Octava de San Camilo del año 1936 en Madrid (1969): Madrid, Alfaguara, 1969 (1 edición), Edición utilizada: Madrid, Alianza editorial, 1979.

- Mazurca para dos muertos (1983). Barcelona: Seix Barral, 1983.

- Cristo versus Arizona (1988). Barcelona: Seix Barral, 1988.

20 MANUEl AlVAR: «Cristo versus Arizona», Blanco y Negro semanario de A.B.C., 31 de julio de 1988, pág. 12.

21 JUAN ANTONIO MASOLIVER RODENAS: «Cela, a las puertas, del deleite obsceno», La vanguardia, 18 de febrero de 1988, pág. 41. 